\title{
Rousseau e a primeira infância
}

Maurício Rebelo Martins

Doutorando da Faculdade de Educação da UNICAMP

Claudio A. Dalbosco

Universidade de Passo Fundo

\section{Resumo}

O presente artigo tem o objetivo de pensar as contribuições de Rousseau para a educação na primeira infância a partir do Livro I do Emílio. Pretende mostrar como o adulto pode ser o mediador do processo em que a criança tomará consciência de sua dependência social e sua autonomia. Rousseau defende que devemos respeitar a natureza da criança e o mundo da criança com suas especificidades. Assim, analisa, num primeiro momento, as necessidades da criança e as especificidades do mundo infantil. Depois, procura entender como Rousseau aborda os cuidados que o adulto deve dispensar a criança nessa fase. E, por fim, busca entender a tensão que surge da necessidade de atender a criança e, ao mesmo tempo, não contaminar o seu mundo com ideais e desejos que fazem parte do mundo do adulto.

Palavras-chave: educação; primeira infância; natureza.

\section{Resumé}

Cet article a l'objectif de penser les contributions de Rousseau pour l'éducation dans la première enfance à partir du livre I d'Émile. Il veut montrer comme l'adulte peut être le médiateur du procès dans lequel l'enfant prendra conscience de son indépendance sociale et de son autonomie. Rousseau défend que nous devons respecter la nature de l'enfant avec ses spécificités. De cette façon, il analyse, dans un premier moment, le besoin de l'enfant et les spécificités du monde enfantin. Après, il cherche à comprendre comme Rousseau aborde les soins que l'adulte doit avoir avec l'enfant dans cette phase. Et, finalement, il cherche à comprendre la tension qui naît du besoin de faire attention à l'enfant et, au même temps, ne pas contaminer son monde avec les idées et les désirs qui font partie du monde de l'adulte.

Mots clés: éducation; première enfance; nature.

Filosofia e Educação - ISSN 1984-9605 - Volume 4, Número 2

Outubro de 2012 - Março de 2013 
Introdução

$\mathrm{N}$

o ano em que se comemoram os 300 anos do nascimento de Jean-Jacques Rousseau e os 250 anos de publicação de seu tratado sobre educação, Emílio, ou Da Educação, não podemos ignorar uma das maiores contribuições desse pensador para a filosofia e para a educação: as suas teses sobre a primeira infância. Muitos dirão que há outras tantas contribuições de Rousseau para se discutir. Não estariam errados. No entanto, foi ele um dos primeiro a pensar cuidadosamente essa fase da vida humana e dar-lhe a devida importância. ${ }^{1}$

Rousseau afirma que precisamos observar e estudar a criança para entendermos o seu desenvolvimento. E foi isso que ele fez. Deste estudo surgiu o conceito moderno de infância. A revolução no conceito de infância concebida por Rousseau foi uma verdadeira revolução copernicana no âmbito da pedagogia infantil. Até então se achava que a criança era um adulto em miniatura ou um adulto defeituoso ${ }^{2}$. Com seu novo modo de ver a infância, passamos a vê-la como uma etapa onde a criança precisa ser respeitada em seu desenvolvimento físico e cognitivo.

$\mathrm{O}$ argumento principal de Rousseau a respeito da infância é que ela é uma etapa que possui suas especificidades e por isso precisa ser estudada com cuidado. A criança precisa ser respeitada em seu próprio mundo que é justamente a infância. A primeira infância, que vai do nascimento aos 2

\footnotetext{
${ }^{1}$ Contrariamente à "educação positiva" que prescrevia à criança o que ela deveria fazer para poder ser "alguém" no futuro, mas sempre de acordo com a concepção do adulto, Rousseau desenvolve o projeto de uma educação negativa (éducation negative), visando possibilitar ao educando o pensar e fazer por si mesmo. Aqui reside certamente o núcleo fundamental de seu pensamento. Para uma leitura de Rousseau nesta perspectiva ver o recente estudo Benner \& Brüggen (2011, p. 75-99).

${ }^{2}$ Isso não significa que antes de Rousseau ninguém tenha se referido a infância como uma fase com especificidades. Alguns autores, como Comenio, escreveram livros para pensar a educação das crianças. No entanto, foi Rousseau quem se dedicou com mais cuidado à análise das características próprias dessa idade.
}

Filosofia e Educação - ISSN 1984-9605 - Volume 4, Número 2

Outubro de 2012 - Março de 2013 
anos, é aquela dedicada a educação do bebê. Poderíamos dizer que é neste período que são lançadas as bases para constituição do ser humano.

Se fossemos avaliar o pensamento filosófico pedagógico de Rousseau com o olhar da pedagogia contemporânea, influenciada, sobretudo pelo pragmatismo e construtivismo pedagógico, certamente que teríamos muitos pontos a serem "corrigidos". Nesse exercício de atualização do pensamento de Rousseau não poderíamos ignorar o quanto seu pensamento solidificou as bases do pensamento pedagógica posterior. Contudo, não é esta a linha a ser seguida neste ensaio, pois, em vez do esforço de atualização de seu pensamento, vamos tratar, neste ensaio, tão somente de alguns aspectos de seu pensamento pedagógico dirigido à primeira infância. Neste sentido, vamos nos concentrar especificamente no primeiro livro do Émile.

\section{1 - A educação na primeira infância: a mais importante}

“A primeira educação é mais importante" (ROUSSEAU, 2004, p. 7) diz Rousseau. Muitos pensadores sustentam que a educação na primeira infância é fundamental para formação da personalidade da criança. ${ }^{3}$ Todos eles inspirados pela observação e estudo da infância feito por Rousseau. Quando Rousseau escreveu o Emílio, defendia que a educação na primeira infância cabia incontestavelmente à mãe e ao pai. Para ele, a relação entre a mãe e o bebê deveria ser sempre garantida. Entretanto, ele mesmo previa a possibilidade da mãe ser substituída pela ama de leite e o pai pelo preceptor. Em nossos dias, como os pais estão delegando a tarefa de educar seus filhos cada vez mais cedo à escola, pensar a educação na primeira infância tornouse uma necessidade premente. Assevera Rousseau:

\footnotetext{
${ }^{3}$ Entre eles cabe destacar, contemporaneamente, Donald Winnicott. Sua ampla produção e seu longo e cuidado trabalho clínico com crianças inspira, numa linha neofreudiana, muito do que se investiga atualmente sobre a educação infantil. Sobre este aspecto ver principalmente seu trabalho $O$ brincar e a realidade (1975), no qual ele desenvolve o conceito de objeto transicional (transitional objects).
}

Filosofia e Educação - ISSN 1984-9605 - Volume 4, Número 2

Outubro de 2012 - Março de 2013 
O mais perigoso intervalo da vida humana é o que vai do nascimento até a idade de doze anos. É o tempo em que germinam os erros e os vícios, sem que tenhamos ainda algum instrumento para destruí-los. E, quando chega o instrumento, as raízes são tão profundas, que já não é tempo de arrancá-las (ROUSSEAU, 2004, p. 96).

Alguns pais já estão delegando a responsabilidade da educação dos seus filhos com dois meses de vida a pessoas, que, por mais preparadas que estejam, não são capazes de substituir a relação fundamental estabelecida entre mãe e filho e pai e filho. É claro que sabemos e entendemos que, na maioria das vezes, as condições de trabalho e outras atividades importantes exigem esse abandono do filho para que os pais possam, inclusive, por na mesa o alimento dos seus filhos. Isto, ao nosso entendimento, só nos mostra de modo mais claro e consistente a importância e a exigência de pensarmos a educação na primeira infância e, de modo especial, o papel do educador. $\mathrm{O}$ alerta, entretanto, é que não podemos esquecer que ser pai e mãe é lindo, mas ao mesmo tempo muito exigente. Além da responsabilidade que temos para com o nosso filho, não podemos esquecer que a educação que vamos dar a ele será responsável pelo tipo de cidadão que ele será. Ou seja, pela sociedade que ele ajudará a edificar.

Para Rousseau, se faz necessário pensar seriamente o significado da infância que começa com o nascimento da criança e que, por sua vez, deve ser também educada a partir deste momento. Por muito tempo se pensou que educar a criança nesta etapa não era uma prioridade. Deveríamos apenas aguardar sua chegada a fase adulta, pois ela era vista como um pequeno adulto defeituoso. Sobre a primeira infância Rousseau dispõe o seguinte:

A primeira educação é mais importante e cabe incontestavelmente às mulheres. Se o autor da natureza houvesse desejado que ela coubesse aos homens, ter-lhes-ia dado leite para alimentar as

Filosofia e Educação - ISSN 1984-9605 - Volume 4, Número 2

Outubro de 2012 - Março de 2013 
crianças. Assim, falai sempre de preferência às mulheres em vossos tratados sobre a educação, pois, além de estarem em condições de tratá-la mais de perto do que os homens e de influenciarem sempre mais, o êxito também lhes interessa muito mais, já que a maior parte das viúvas se acha como que à mercê dos filhos e eles então lhe fazem sentir vivamente, no bem e no mal, o efeito da maneira como foram criados (ROUSSEAU, 2004, p. 7-8).

Para Rousseau, os papéis que o educador e os pais assumem fazem parte de um projeto mais amplo e muito importante. Esse projeto visa à formação de um cidadão autônomo e preparado para reformar a sociedade. Ou seja, ele entende que o papel da educação é ensinar um indivíduo a ser homem, a ser humano: um homem capaz de participar da república de modo autônomo e soberano e de submeter-se livremente à vontade geral. Sobre isto fala Rousseau:

$\mathrm{Na}$ ordem natural, sendo os homens todos iguais, sua vocação comum é a condição de homem, e quem quer que seja bem educado para tal condição não pode preencher mal as outras relacionadas com ela. Pouco me importa que destinem meu aluno à espada, à Igreja ou à barra. Antes da vocação dos pais, a natureza o chama para a vida humana. Viver é o ofício que quero ensinar-lhe. Ao sair de minhas mãos, concordo que não será nem magistrado, nem soldado, nem padre; será homem, em primeiro lugar (ROUSSEAU, 2004, p. 14-15).

Assim, em primeiro lugar, temos de educar a criança para ser humana, pois ela nasceu para isso. Rousseau quando fala de uma educação natural não quer que sejamos como os animais. Natural para nós humanos é sermos humanos. ${ }^{4}$ Diferente do que muitos pensavam na época, Rousseau acredita

\footnotetext{
${ }^{4}$ Quando recorre à ordem natural e insiste na precedência da formação humana na educação da criança, Rousseau está se opondo ao tipo de educação voltado ao despertar a vocação nas crianças. A educação voltada exclusivamente às vocações significava, em última instância, uma atitude autoritária do adulto em relação à criança, pois projeta ao mundo da criança uma ideia de futuro que lhe é estranho. De outra parte, uma educação orientada pela "ordem natural" remonta a uma longa tradição, de origem grego-romana. Sobre isso ver a primeira parte do livro Educação natural em Rousseau: das Necessidades da criança e dos cuidados do adulto, de autoria de Dalbosco (2011).
}

Filosofia e Educação - ISSN 1984-9605 - Volume 4, Número 2

Outubro de 2012 - Março de 2013 
que não podemos nos descuidar da educação nessa fase, pois podemos estar ali criando ou um tirano ou um escravo.

\section{2 - As necessidades da criança}

O princípio fundamental da educação natural na primeira infância para Rousseau é o respeito do adulto ao mundo ${ }^{5}$ da criança. Esse respeito deve começar por aceitar que a criança tem seu próprio mundo e um modo próprio de nele viver. Devemos entender que a criança não é um adulto em miniatura. A criança é um ser que está vivendo uma fase especial e deve receber a atenção e o respeito que uma criança merece. Diz Rousseau:

Para não corrermos atrás de quimeras, não nos esqueçamos do que convém à nossa condição. A humanidade tem seu lugar na ordem das coisas, e a infância tem o seu na ordem da vida humana: é preciso considerar o homem no homem e a criança na criança. Determinar para cada qual o seu lugar e ali fixá-lo, ordenar as paixões humanas conforme a constituição do homem, é tudo o que podemos fazer pelo seu bem estar. (ROUSSEAU, 2004, p. 73-74).

Podemos destacar três ideias importantes presentes nesta passagem. Em primeiro lugar, Rousseau indica que não podemos tomar apenas a humanidade quando pensamos no processo formativo do ser humano. Devemos considerar, também, as relações que ele estabelece. Em segundo lugar, já na infância é preciso que a criança, reconhecendo-se indefesa e com necessidades, entenda que faz parte de uma ordem das coisas que não inclui apenas a espécie humana. Ou seja, é preciso que, aos poucos, ela vá percebendo que pertence a uma ordem maior e que é responsável por ela também. Sua noção de sentir-se bem com os outros e com o mundo depende fundamentalmente da noção de pertença a esta ordem das coisas e o respeito

\footnotetext{
${ }^{5}$ Ao falarmos do mundo da criança, estamos nos referindo a uma fase que contem as suas especificidades e condições especiais.
}

Filosofia e Educação - ISSN 1984-9605 - Volume 4, Número 2

Outubro de 2012 - Março de 2013 
que adquire por ela. Daí que a educação natural seja, em sua inteireza, uma educação pelas coisas e não uma educação orientada pelos vícios adultos.

Em terceiro lugar, Rousseau está preocupado em garantir que a criança seja respeitada em seu mundo. A infância ocupa um lugar específico na ordem das coisas. É um erro antecipar etapas. É uma ofensa ao mundo da criança querer que elas desenvolvam agora algumas capacidades que só mais tarde poderão desenvolver. Atualmente vemos muitos pais que sacrificam a infância dos seus filhos colocando-os em cursos muito cedo, sob o pretexto de que eles venham a ter um futuro melhor e mais feliz. Para nosso autor, não podemos sacrificar a infância sob a desculpa de que colheremos os frutos no futuro. Sobre isto afirma Rousseau:

Que devemos pensar, então, dessa educação bárbara que sacrifica o presente por um futuro incerto, que prende uma criança a correntes de todo tipo e começa por torná-la miserável, para lhe proporcionar mais tarde não sei que pretensa felicidade de que provavelmente não gozará jamais? Mesmo que eu considerasse razoável essa educação por seu fim, como encarar sem indignação essas pobres infelizes submetidas a um jugo insuportável e condenadas a trabalhos contínuos como os galeotes, sem ter certeza de que tantos trabalhos algum dia lhes serão úteis! A idade da alegria passa-se em meio a prantos, a castigos, a ameaças, à escravidão (ROUSSEAU, 2004, p. 72).

Aqui, Rousseau faz uma séria crítica à educação jesuítica, a qual ele chama de educação bárbara. Para ele, é incompreensível que castiguemos a criança em nome de algo que ela não está preparada para ser nem física e nem cognitivamente. Os jesuítas educavam as crianças como uma espécie de adulto defeituoso. Assim, o papel da educação seria corrigir esses defeitos para daí surgir um verdadeiro adulto. Rousseau acreditava que ao fazer isso estavam corrompendo a verdadeira natureza da criança, pois postulavam inserir no seu mundo ideias e ideais que ela sequer entenderia.

Filosofia e Educação - ISSN 1984-9605 - Volume 4, Número 2

Outubro de 2012 - Março de 2013 
Respeitar a criança em seu mundo significa não sacrificar esta etapa tão importante para o desenvolvimento da criança. Ou seja, cada fase da vida deve ser vivida com toda a intensidade que lhe cabe. Contra a educação bárbara, Rousseau acredita que a criança deve brincar, deve errar, deve acertar, deve ser criança. Isso não significa, contudo, que devemos eliminar do mundo da criança o esforço, as dificuldades e as privações. ${ }^{6}$ Se fizermos isto começamos a contaminar o mundo da criança.

Considerar a criança em seu próprio mundo é, antes de tudo, estar atento as suas particularidades e, de modo especial, as suas necessidades naturais. Para Rousseau, ao nascer, a criança começa a conhecer as suas fraquezas. Ou seja, ela percebe que possui necessidades físicas que precisam ser atendidas. $\mathrm{O}$ educador pode sentir-se tentado a facilitar a vida da criança. Porém, se ceder a está tentação, poderá criar nela necessidades e desejos artificiais. Convém ao educador observar quais são as verdadeiras necessidades e qual é o momento certo para intervir.

Entender as necessidades reais ${ }^{7}$ da criança é fundamental para pensar a intervenção do adulto no seu mundo. A criança descobre aos poucos que possui necessidades. Percebe que é fraca, que lhe falta algo e que não sobreviveria sem ajuda dos outros. Contudo, ela não está em condições de saber diferenciar o que é necessidade real do que é necessidade artificial. Nesse caso, é tarefa do adulto ajudá-la a satisfazer as necessidades reais e a não desenvolver as necessidades artificiais.

\footnotetext{
${ }^{6}$ Pelo contrário, o núcleo da educação natural, orientado pela educação das coisas, precisa criar o ambiente pedagógico necessário para que a criança, desde muito cedo seja exposta, com todo o cuidado possível, às intempéries e forças da natureza. Como a meta da educação da criança, em sua fase inicial, é o fortalecimento do corpo e o refinamento dos sentidos, então ela precisa ser "jogada" para o meio das coisas, desenvolvendo sua estrutura sensitiva a partir da ordem das coisas. Para uma reflexão detalhada nesta direção ver o estudo de Schäfer (2002).

${ }^{7}$ As necessidades reais, de modo especial, são as necessidades físicas e biológicas. Já as necessidades da fantasia, são aquelas que representam a contaminação do mundo da criança por parte do adulto ou aqueles "desejos caprichosos" que ela cria por meio da sua imaginação.
}

Filosofia e Educação - ISSN 1984-9605 - Volume 4, Número 2

Outubro de 2012 - Março de 2013 
Na infância, Rousseau também acredita que devemos prioritariamente desenvolver os sentidos da criança por meio do confronto dela com a natureza e com as coisas. Esse caminho não deve ser percorrido ou mesmo abreviado pelo adulto. A criança precisa do adulto, mas ele não deve interferir nesse processo arbitrariamente. O papel do adulto é conduzir esse enfrentamento dela com a natureza. Desse modo, o adulto conduz, mas é a criança que deve percorrer o caminho do desenvolvimento dos sentidos por conta própria.

A educação na primeira infância deve considerar as necessidades da criança, mas o educador e os pais não devem impedir a criança de conhecer o mundo físico. A infância é a fase onde devemos estimular os sentidos da criança sem por ela fazer as experiências. A criança, na primeira infância, não deve saber senão aquilo que ela experimentou pelos sentidos. Devemos permitir que ela entre em contato com a natureza e com as coisas. Proteger excessivamente a criança é impedi-la de ser criança. A proteção excessiva pode impedi-la de aprender a viver com a dor e com as dificuldades. Isto é errado, pois como foi dito antes, a criança precisa conhecer a força da natureza e as suas próprias limitações.

O grande problema é que costumamos analisar a infância sempre tomando o adulto por modelo. Assim, costumamos olhar para criança para ver o que lhe falta para ser adulto. Vemos na criança apenas a incompletude. Rousseau é o precursor da ideia de procurar na criança a criança. Para ele, é um desacerto olharmos para criança e procurarmos o adulto. Aliás, nessa procura, acabamos por acelerar o desenvolvimento da criança de maneira indiscriminada, autoritária e viciada. Já no prefácio do Emílio Rousseau fala sobre esse problema:

Não se conhece a infância; no caminho das falsas ideias que se têm, quanto mais se anda, mais se fica perdido. Os mais sábios

Filosofia e Educação - ISSN 1984-9605 - Volume 4, Número 2

Outubro de 2012 - Março de 2013 
prendem-se ao que aos homens importa saber, sem considerar o que as crianças estão em condições de aprender. Procuram sempre o homem na criança, sem pensar no que ela é antes de ser homem (ROUSSEAU, 2004, p. 4)

A infância é a fase durante a qual a criança deve ser livre para conhecer as suas próprias forças. O único obstáculo que a criança deve conhecer é aquele advindo da natureza e, principalmente, das suas próprias forças. Ou seja, ela deve fazer somente aquilo que as suas forças lhe permitem realizar naturalmente. Assim, a liberdade de uma criança nunca é limitada pela intervenção arbitrária do adulto.

\section{3 - Os cuidados do adulto}

Rousseau começa por falar da necessidade de respeitarmos a criança no seu mundo. Ou seja, devemos deixar a criança ser criança. No entanto, o próprio Rousseau alerta que isso não significa que o adulto deve abandonar a criança e deixá-la fazer o que bem entender. A infância se caracteriza por ser uma fase de necessidades. A criança é um ser dependente. Por isso Rousseau admite a indispensabilidade da intervenção do adulto no mundo da criança. Sua defesa enérgica a favor do mundo da criança não significa a desresponsabilização da intervenção do adulto.

A questão aqui é que Rousseau é contra toda forma de autoritarismo e espontaneísmo na educação. Ou seja, nem podemos arbitrariamente intervir no mundo da criança e nem podemos deixar a criança abandonada a sua própria sorte, pois não devemos abandonar um ser frágil e absolutamente dependente de nossa atenção. Dispensar cuidados a criança na primeira infância constitui-se numa tarefa irrevogável. Contudo, desta tarefa indispensável surge uma tensão que nos parece indissolúvel.

A tensão que surge aqui pode ser resumida do seguinte modo: não podemos corromper o mundo da criança, mas também devemos dispensar

Filosofia e Educação - ISSN 1984-9605 - Volume 4, Número 2

Outubro de 2012 - Março de 2013 
cuidados à criança. A tensão que surge é um problema que todo aquele que pensa em educar para autonomia precisa enfrentar. Isso porque, toda vez que pretendemos educar para autonomia, podemos estar inserindo ideais e ideias no mundo da criança que ela deveria por conta própria construir. ${ }^{8}$

Rousseau teme que essa intervenção possa corromper a criança já que o adulto projeta no mundo dela os seus ideais, as suas experiências e as suas crenças. Podemos, ao intervir no seu mundo, ao pô-la em contato com os nossos hábitos, corromper o seu caráter. Ele afirma que:

O único hábito que devemos deixar que a criança adquira é o de não contrair nenhum. [...] Preparai à distância o reinado de sua liberdade e o uso de suas forças, deixando em seu corpo o hábito natural, colocando-a em condições de sempre ser senhora de si mesma e de fazer em todas as coisas a sua vontade, assim que a tiver (ROUSSEAU, 2004, p. 49).

Entretanto, se o adulto não dispensar cuidados à criança, pode também formar uma criança que será um adulto que não conhece regras. É preciso ter o cuidado para não criar nem um escravo e nem um tirano. Embora Rousseau considere importante o respeito ao mundo da criança, ele também nos alerta para o perigo de não dispensarmos cuidados a formação da criança. Rousseau não enfraquece o papel do adulto e, nesse sentido, o educador tem a responsabilidade de educar a vontade ainda desregrada da criança.

Para lidar com essa tensão, ele pensa que é fundamental que a relação entre adulto e criança se de autonomamente. É só pela relação autônoma que a criança poderá por conta própria construir sua emancipação. Ou seja, a

\footnotetext{
${ }^{8}$ Sobre este ponto repousa um dos principais dilemas das teorias educacionais críticas que visam a autonomia e maioridade dos envolvidos no processo pedagógico. No caso específico da educação infantil, o problema inicial consiste em saber como educar para a maioridade um ser que ainda não está em condições de pensar por conta própria. Sobre as aporias internas de uma educação para a maioridade ver o excelente trabalho de Heinz Eidam (2009, p. 51-88).
}

Filosofia e Educação - ISSN 1984-9605 - Volume 4, Número 2

Outubro de 2012 - Março de 2013 
criança deve ser educada na liberdade. Desse modo, isso impede que ela escravize o adulto ou que ela seja escravizada por ele.

Aquele educador ou pai que negligenciar suas responsabilidades ou aquele que proteger excessivamente a criança, estará afastando a criança da sua verdadeira natureza. Nem excesso e nem falta. Lidar com esta tensão entre as necessidades e os cuidados não é nada fácil. $\mathrm{O}$ educador deve ser capaz de identificar a hora em que verdadeiramente a criança precisa de uma intervenção no seu mundo. Rousseau prefere não dizer quando podemos intervir. Para ele, é mais fácil dizer quando o educador não deve intrometerse. Desse modo, ele destaca que o educador não deve intervir quando a criança estiver experimentando o mundo e as coisas por conta própria.

Parece-nos, portanto, que fica evidente a tensão inerente às teses de Rousseau: de um lado, a criança sozinha não sobrevive e precisa dos cuidados do adulto; de outro, esses cuidados podem corromper o mundo da criança. Entendemos que Rousseau, de algum modo, tenta relaxar essa tensão com a tese de uma liberdade bem regrada. Ou seja, é preciso o respeito ao mundo da criança, mas isso não significa enfraquecer o papel do adulto ou do educador. Pelo contrário, o educador desempenha um papel fundamental, pois ajuda a criança desenvolver suas disposições naturais e ter consciência de que a boa liberdade é aquela que não dispensa as regras.

A tensão entre as necessidades da criança e os cuidados do adulto serve para entendermos que os pais ou educadores precisam ser no mínimo perspicazes para conduzir a educação das crianças. Ter paciência para agir na hora certa, ser sereno e firme são qualidades necessárias para conduzir a educação nessa fase. É essa tensão, entre satisfazer as necessidades naturais da criança e o cuidado para não corromper seu mundo, que deve manter o educador cuidadoso. 
Como dissemos antes, a educação da criança na primeira infância principia pelos sentidos. Isso significa que o educador e os pais não devem precipitar o desenvolvimento da razão. O educador, de modo especial, deve afastar todos os obstáculos que impeçam seu educando de trilhar seu próprio caminho. Mesmo assim, o educador não pode facilitar a vida do seu educando, pois o educando deve experimentar as dificuldades impostas pelo confronto com a natureza e com as coisas. O educador deve ser aplicado, mas também deve ser cauteloso. $\mathrm{O}$ educador não deve se apressar em agir a não ser para evitar que outros venham a contaminar o mundo da criança.

Ora, se lidar com esta tensão entre as necessidades da criança e os cuidados do adulto não é nada fácil, mas necessário, então, Rousseau, ao final do seu primeiro livro, apresenta as máximas da educação natural na primeira infância:

Longe de terem forças supérfluas, as crianças nem mesmo têm forças suficientes para tudo o que a natureza lhes exige. É preciso, portanto, facultar-lhes o emprego de todas as forças que ela lhes dá e de que não poderiam abusar. Primeira máxima.

É preciso ajudá-las e suprir o que lhes falta, quer em inteligência, quer em força, em tudo o que diz respeito à necessidade física. Segunda máxima.

No auxílio que lhe prestamos, devemos limitar-nos unicamente ao realmente útil, sem nada conceber à fantasia ou ao desejo irrazoável, pois a fantasia não as atormentará enquanto não se a fizer nascer, dado que ela não pertence à natureza. Terceira máxima.

É preciso estudar com atenção sua linguagem e seus sinais, para que, numa idade em que elas não sabem fingir, distingamos em seus desejos o que vem imediatamente da natureza e o que vem da opinião. Quarta máxima. (ROUSSEAU, 2004, p. 58).

Com essas máximas, Rousseau parece esclarecer que o papel do educador é não atrapalhar o desenvolvimento natural da criança. O objetivo

Filosofia e Educação - ISSN 1984-9605 - Volume 4, Número 2

Outubro de 2012 - Março de 2013 
é permitir que as crianças aprendam a fazer as coisas mais por si mesmas e menos com a ajuda dos outros. É importante desde cedo que a criança perceba, por conta própria, as limitações que a natureza lhe impõe. Ao educador cabe suprir o que falta a criança em relação as suas necessidades naturais. Isso significa que o educador deve ter o cuidado para não criar necessidades artificiais e muito menos atender as necessidades deste tipo. Para tanto, é muito importante que o educador preste atenção ao choro e aos sinais que a criança emite de modo que possa perceber o que é natural e o que é artificial.

O choro é o modo como a criança de zero a dois anos se comunica. Ele é fundamental para entendermos como podemos lidar com a tensão inerente a educação das crianças nessa fase. É pelo choro que a criança revela o seu mundo e inicia o seu processo de socialização. "Desse choro, que acreditamos ser tão pouco digno de atenção, nasce a primeira relação do homem com tudo que o cerca. Aqui se forja o primeiro elo da longa cadeia de que é formada a ordem social (ROUSSEAU, 2004, p. 54). Se elas sentem fome ou frio, choram. Se quiser algo e perceber que sozinha não pode alcançar, também chora. Sua condição é a de um ser frágil e de necessidades. O choro é o meio que ela encontra para solicitar a ajuda do adulto.

O educador cauteloso saberá distinguir o choro que é um pedido do choro que é uma ordem. Por isso que resolver a tensão entre as necessidades da criança e os cuidados do adulto é tão importante. O educador precisa sempre estar atento para atender a criança naquilo que é real. Mas também estar atento para não desenvolver na criança desejos ou ideais que não pertencem a sua natureza. É evidente que nos sentimos sempre tentados a atender ou a ajudar a criança. Contudo, se queremos um homem forte e 
capaz de ser senhor de si mesmo, devemos agir com calma e sabedoria na condução do seu desenvolvimento.

O choro pode servir para demonstrar a dependência da criança em relação ao adulto. Pode servir também para a criança tornar o adulto seu servo. Visando a educação de um indivíduo que será responsável pela sociedade em que irá viver, a criança tem que aprender desde cedo que não é senhora nem dos homens e nem das coisas. Ela tem que aprender que não pode submeter ninguém as suas ordens. Ao adulto, cabe observar com atenção quando o choro é uma manifestação de uma necessidade natural e não um desejo artificial.

Assim, todo projeto de uma educação na primeira infância se desdobra em dois grandes princípios: Primeiro, devemos ajudar as crianças a satisfazer suas necessidades naturais e a desenvolver suas disposições naturais; segundo, devemos ter o cuidado para não projetar ideais adultos que possam contaminar seu mundo e criar desejos artificiais. Por isso, tomar a tensão entre as necessidades da criança e os cuidados do adulto, pode nos ajudar a entender como a educação para a autonomia já deve começar na primeira infância.

Entretanto, Rousseau não quer com isso preconizar que a criança deve fazer o que bem entender e nem que o papel do adulto ou do educador seja dispensável. Para ele, a exigência do respeito ao mundo da criança é só mais um desafio para o educador, pois a criança precisa da sua ajuda. A criança como um ser frágil e de necessidades precisa dos cuidados do adulto. Não é a criança que deve conduzir sua educação. Cabe ao adulto, ao mesmo tempo, ter o cuidado para não corromper o mundo dela e ajudá-la a crescer com autonomia e com a consciência de uma liberdade bem regrada. $\mathrm{Ou}$ seja, que ela cresça com a consciência de que a melhor das liberdades é aquela que não dispensa as regras.

Filosofia e Educação - ISSN 1984-9605 - Volume 4, Número 2

Outubro de 2012 - Março de 2013 
Essas regras, por assim dizer, ajudam a criança a experimentar a autonomia. Rousseau acredita que buscar a autonomia é o dever de todo homem. Esse, aliás, é o ideal iluminista por excelência. Contudo, poderíamos questionar como é possível educar na e para autonomia na primeira infância, se a criança ainda não é capaz de entender o que significa ser autônoma? Para Rousseau, a autonomia não precisa ser entendida pela criança, mas pode ser experimentada.

A autonomia não se limita ao pensar por si mesmo. No caso da primeira infância, ela está relacionada à satisfação das necessidades naturais da criança. Ela nasce e percebe aos poucos que é dependente dos cuidados de outrem. O problema é que, ao dispensar os cuidados, o adulto pode contaminar a criança com necessidades artificiais e ou tornar-se escravo dela. O modo como são educadas as necessidades é que faz aos poucos a criança saborear a autonomia. A questão da autonomia só pode ser compreendida adequadamente no contexto da tensão entre as necessidades da criança e os cuidados do adulto. Desse modo, pensar sobre a autonomia na primeira infância significa pensar sobre a necessidade e sobre o cuidado.

A criança nasce livre. Mas essa sua liberdade é desregrada. Ela não conhece limites. É aqui que encontramos a importância de outra tese central do projeto de Rousseau: educar para uma liberdade bem regrada. A criança precisa aprender a viver já na infância com as regras mínimas. Cabe ao adulto mediar a descoberta dessas regras. Entretanto, é muito importante que essas regras não sejam impostas arbitrariamente pelo adulto, mas que ele ajude a criança a perceber que há forças naturais que limitam a sua liberdade.

Com a liberdade natural a criança não conhece regras. Rousseau acredita que o adulto deve contribuir para transformar essa liberdade natural numa liberdade regrada. A criança precisa entender que há limites para as

Filosofia e Educação - ISSN 1984-9605 - Volume 4, Número 2

Outubro de 2012 - Março de 2013 
suas ações no mundo. Ela tem que entender que não pode fazer tudo que deseja. Assim, aos poucos, com a mediação do adulto, ele deve perceber que os seus desejos se limitam às suas forças. Afirma Rousseau a respeito de suas máximas:

O espírito destas regras é dar às crianças mais verdadeira liberdade e menos domínio, deixar que façam mais por si mesmas e exijam menos dos outros. Assim, acostumando-se cedo a limitar os seus desejos às suas forças, pouco sentirão a privação do que não estiver em seu poder (ROUSSEAU, 2004, p. 58).

Rousseau parte do princípio de que temos de conciliar o valor absoluto da liberdade com o valor das regras corretas. Jamais podemos deixar de ser livres, mas como nascemos para viver em sociedade, não podemos abrir mão das regras. Nesse sentido é que experimentamos a autonomia já na infância, pois a regra válida é aquela que o próprio sujeito vê a necessidade de impor a si mesmo. É evidente que a criança não toma consciência da autonomia como o adulto. Contudo, é importante que ela comece a sentir desde cedo o que ela pode fazer e o que não pode fazer.

Por isso, é preciso inserir a educação na primeira infância dentro de um projeto mais amplo na obra de Rousseau. Nosso autor acredita que a sociedade é responsável pelas mais profundas feridas causadas ao homem. Entretanto, como afirma Cassirer, é só a sociedade que pode curar essas feridas (CASSIRER, 1999, p. 74). A educação natural da criança permitirá que ela cresça firme de caráter e capaz de reformar essa sociedade corrupta. Para Rousseau, basta deixar o homem ser autêntico, autônomo e livre que ele saberá o que fazer pela sua sociedade.

Deste modo constitui-se o projeto de Rousseau para a primeira infância: a criança deve ser criança. Mas ao sentir que não pode satisfazer suas necessidades sozinha, precisará solicitar os cuidados do adulto. Ao

Filosofia e Educação - ISSN 1984-9605 - Volume 4, Número 2

Outubro de 2012 - Março de 2013 
adulto, cabe ajudar a criança sem corromper o seu mundo e a interpretar o choro para saber quais são as necessidades reais que precisam ser atendidas. Mais importante ainda, é ser o mediador do processo em que a criança tomará consciência da sua dependência social e da sua autonomia.

\section{Referências}

BENNER, D. \& BRÜGGEN, F. Geschichte der Pädagogik. Vom Beginn der Neuzeit bis zur Gegenwart. Stuttugart: Reclam, 2011.

CASSIRER, Ernst. A questão Jean-Jacques Rousseau. São Paulo: UNESP, 1999. DALBOSCO. Educação natural em Rousseau: das necessidades da criança e dos cuidados do adulto. São Paulo: Cortez Editora, 2011.

EIDAM, H. "Educação e maioridade em Kant e Adorno". In: DALBOSCO, C. A. \& EIDAM, H. Moralidade e educação em Immanuel Kant. Ijui: Editora UNIJUI, 2009, p. 51-88.

ROUSSEAU, Jean-Jacques. Emílio on Da Educação. São Paulo: Martins Fontes, 2004.

SCHÄFER, A. Jean-Jacques Rousseau. Ein pädagogisches Porträt. Weinheim und Basel: Beltz Verlag, 2002.

WINNICOTT, D. O brincar \& a realidade. Rio de Janeiro: Imago, 1975. 